\title{
Sensorineural Hearing Loss and Its Relationship with Duration of Chelation Among Major $\beta$ - Thalassemia Patients
}

Muhammad Ali Khan ${ }^{1}$, Mahrukh A. Khan ${ }^{2}$, Ahmed M. Seedat ${ }^{3}$, Maria Khan ${ }^{2}$, Sana F. Khuwaja ${ }^{4}$, Ram Kumar $^{5}$, Syed Muhammad Usama ${ }^{6}$, Sundus Fareed ${ }^{7}$

1. Otolaryngology, Dow University of Health Sciences, Karachi, PAK 2. Internal Medicine, Dow University of Health Sciences, Karachi, PAK 3. Family Medicine, Dow University of Health Sciences, Karachi, PAK 4. Family Medicine, Dow University of Health Sciences, Karachi , PAK 5. Internal Medicine, Chandka Medical College, Larkana, PAK 6. Miscellaneous, Dow University of Health Sciences, Karachi, PAK 7. Internal Medicine, Civil Hospital Karachi, Karachi, PAK

Corresponding author: Sundus Fareed, sundus_fareed@yahoo.com

\begin{abstract}
Introduction

Thalassemia is a common genetic disorder worldwide, also occurring frequently in Karachi, Pakistan. Beta $(\beta)$-thalassemia major patients need repeated transfusions which cause iron overload. Patients are treated with chelating agents to reduce the high serum ferritin level and to decrease morbidity and mortality due to increased iron levels. This combined therapy also leads to some complications. One of them is the sensorineural hearing loss (SNHL). To date, no data is available in Pakistan regarding SNHL among major $\beta$ thalassemia patients on chelating therapy.
\end{abstract}

Methods

A cross-sectional study was performed in collaboration with the Thalassemia Center and Dr. Ruth Pfau at the Department of Ear, Nose, and Throat, Civil Hospital, Karachi, Pakistan. The variable to detect hearing was pure tone air and bone conduction thresholds at the frequencies of $250-4,000 \mathrm{~Hz}$. Clinical data, such as chelating agent dose, duration, and hearing status, were recorded. Demographic characteristics, like age, gender, height, and weight, were noted. The hemoglobin and serum ferritin levels of the subjects were also included.

Results

Forty-five percent of cases of thalassemia were suffering from SNHL. In the right ear, the Pearson correlation of chelating agent dose $(\mathrm{mg})$ with SNHL was mildly positive and statistically significant $(\mathrm{r}=$ $0.261, \mathrm{p}<0.001),(\mathrm{r}=0.337, \mathrm{p}<0.001),(\mathrm{r}=0.198, \mathrm{p}=0.005)$, and $(\mathrm{r}=0.207, \mathrm{p}=0.003)$ at the frequencies of $250,500,1,000$, and 2,000 Hz, respectively, and the Pearson correlation of chelating agent used (in months) with SNHL was mildly positive and statistically significant $(r=0.232, p=0.001)$, and $(r=0.301, p<0.001)$ at frequencies 250 to $500 \mathrm{~Hz}$, respectively. In the left ear, the Pearson correlation of chelating agent dose (mg) with SNHL was mildly positive and statistically significant, $(r=0.191, p=0.007),(r=0.202, p=0.004),(r=$ $0.297, \mathrm{p}<0.001),(\mathrm{r}=0.183, \mathrm{p}=0.010)$ and $(\mathrm{r}=0.221, \mathrm{p}=0.002)$ at frequencies $250,500,1,000,2,000$, and $4,000 \mathrm{~Hz}$, respectively, and Pearson correlation of chelating agent used (months) with SNHL was mildly positive and statistically significant only at the frequency of $2,000 \mathrm{~Hz}(r=140, p=0.049)$.

Conclusion

Chelation therapy and regular blood transfusions, apart from prolonging the life of thalassemic patients, also leads to some complications. With this survey, it was concluded that almost half of the patients had normal hearing, while the other half had sensorineural hearing loss after the use of deferasirox. It is inferred that the incidence of SNHL is not only dose-related but the duration of use of a chelating agent is also a contributing factor.

Categories: Internal Medicine, Otolaryngology

Keywords: chelation complications, $\beta$-thalassemia, sensorineural hearing loss, chelating agent, pure tone audiogram, iron chelation, pakistan

\section{Introduction}

Thalassemia is a hematologic disease first discovered by Thomas Cooley and Lee in 1925 [1]. It is estimated that $5 \%-7 \%$ of the world's population is affected by a hemoglobin $(\mathrm{Hb})$ disorder [2]. About $3 \%$ of carriers are 
found worldwide with around 60,000 babies being born with genetic mutations resulting in $\beta$-thalassemia [3]. It is one of the common disorders in the Mediterranean area [4], the Indian subcontinent, Southeast Asia, West Africa [5], and the Middle East, as well as affecting other countries due to migration [6]. The carrier rate in Pakistan is about $5 \%-8 \%$, meaning that up to 9.8 million of the population is affected with around 5,000 babies being diagnosed with the disorder [7]. Consanguinity is a major cause of inheritance of this disease in Pakistan [8]. Thalassemia is a disease characterized by dysfunctional Hb chain formation [5]. It is an autosomal recessive inherited disorder which results in the defective formation of the globin chains manifesting as hypochromic, hemolytic anemia [9]. Thalassemia is among the most common genetic disorders worldwide. Among them, $1.67 \%$ of the population is heterozygous and $0.44 \%$ of the population is homozygous for alpha and $\beta$-thalassemia [10-11]. Alpha-thalassemia is due to absent or reduced synthesis of the alpha-globin chain involving deletion of genes on chromosome 16 [12].

$\beta$-thalassemia is a hemoglobinopathy which arises due to a mutation in the $\mathrm{Hb}$ subunit $\beta$ gene on chromosome 11 [10]. It is characterized by the absence or a deficiency in the formation of $\beta$ globin chains which results in lower $\mathrm{Hb}$ levels, resulting in less than efficient transport of oxygen throughout the body; this results in damage to the body due to long-term ischemia and oxygen deprivation of organs and bones, potentially leading to stroke and other complications [13-14]. There are three variants of the disease: $\beta$ thalassemia major (a homozygous form which is a severe transfusion-dependent anemia because of the mutation of both of the $\beta$ globin genes), $\beta$-thalassemia intermedia (the mutation is on both globin genes but one is severe and the other one is mild), and $\beta$-thalassemia minor (usually asymptomatic and exists as a carrier state with the mutation present in one gene) [10].

The aim of treatment of thalassemia is regular blood transfusions to overcome the reduced blood-making capacity of the body and chelation therapy to decrease the iron load in the body secondary to transfusion and hemolysis. This has helped in adding a number of years to the lives of the diseased. The only definitive cure for thalassemia is bone marrow transplant [15]. The calculation of the serum ferritin level is the most appropriate test to estimate iron overload in $\beta$-thalassemia major patients. A desired and safe ferritin level of $1,000 \mathrm{mg} / \mathrm{L}$ is generally advocated as a standard practice in thalassemia major and other situations of increased iron from a blood transfusion. When serum ferritin levels approach $1,000 \mathrm{ng} / \mathrm{L}$, this is commonly taken as a stage to begin iron chelation therapy. The main principle of chelation is to maintain a safe iron level threshold to protect the body from developing complications [16].

The introduction of deferoxamine (DFO) (Desferal ${ }^{\circledR}$, Novartis Pharma Stein AG, Stein, Switzerland) has been a revolution in the field of thalassemia and is the most common iron-chelating agent in use. It reduces cardiac and hepatic disorders and reverses the endocrine dysfunction. However, it can only be administered parenterally and is costly, which reduces its compliance [17]. One study suggested that around $27 \%$ of the developed complications are related to hearing on low doses of chelation [18]. A study done by Cohen et al. suggested that there are noticeable side effects on lower doses of DFO but major side effects occur on higher doses, affecting the hearing and resulting in sensorineural hearing loss (SNHL) and induced retinal damage resulting in vision loss later on in life [19].

Similarly, many new oral chelating agents have been introduced in the market, such as deferiprone (DFP) (Ferriprox ${ }^{\circledR}$, ApoPharma USA, Inc., Rockville, MD) and deferasirox (DFX) (Exjade ${ }^{\circledR}$, Novartis Pharma Stein AG, Stein, Switzerland), that have relatively fewer side effects than DFO [20]. Adverse side effects of DFP include agranulocytosis which ranges for nine days and is not as severe but has resulted in some deaths and knee arthropathy for which the drug administration was stopped. Gastrointestinal distress, rash, rise in creatinine levels, and liver problems arise with DFX use. Auditory disturbances have been reported when treated with these agents for a long duration of time at high doses and in patients with increased ferritin levels. In most of the cases, the damage was reversible with immediate cessation of the treatment [21]. In our country, no such data is available for SNHL in $\beta$-thalassemia patients. It is necessary to study the relationship of SNHL with the duration of use of chelating agents in order to establish newer and better hearing monitoring protocols and improve the quality of life of these patients.

In their 2017 study, Derin et al. highlighted the controversy regarding the ototoxicity of chelating agents [22]. Hence, it is important to identify the high-risk group of patients who are prone to develop SNHL and its relationship with the duration of use.

So far, no data is available regarding SNHL among the $\beta$-thalassemia major population in Pakistan. It is important to study the relationship of SNHL with the duration of use of chelating agents, especially when there is a relatively large and adequate population of these patients available, providing insight on how to manage their anemia, along with the complications implicated by the treatment.

The importance of establishing a relationship of SNHL with the duration of use of chelating agents cannot be emphasized enough. Hence, it was imperative to collect such data by conducting this study in order to provide the relationship of SNHL with the duration of use of chelating agents to help to reduce the risk of such complications by adjusting the duration of their treatment and to make changes in their lifestyle and treatment when necessary. This study was aimed to confirm chelating agents induced auditory neurotoxicity and the necessity of periodic audiological control of $\beta$-thalassemia patients for prompt diagnosis and 
management.

\section{Materials And Methods}

A cross-sectional study was conducted from January 2014 until December 2017 in collaboration with the Thalassemia Center and the Department of Ear, Nose, and Throat (ENT), Dr. Ruth Pfau, Civil Hospital, Karachi, Pakistan. The study was approved by the Institutional Review Board of Dow University of Health Sciences.

Patients with $\beta$-thalassemia major between the ages of five to 25 years who visited clinics for treatment within six months of the start of the study and with no preexisting ear disease were included after informed consent and/or assent from the parents/guardians. Individuals exposed to ototoxic medications other than DFX, cases of congenital hearing loss, acute and chronic otitis media, tympanic membrane perforation found on otoscopic examination, and cases with a history of ear surgeries were all excluded.

A sample size of 200 was calculated using a cross-sectional single population formula with $99.99 \%$ confidence interval (CI), prevalence (3.5\%), and margin of error (5\%). Initially, 208 participants were selected for the study but 10 patients were excluded because of non-compliance and language barriers [23].

Written informed consent was taken, and the procedure and protocols of pure tone audiometry (PTA) (Beltone, Model \#120) were thoroughly explained to the patient and/or parents/guardians. Each selected patient underwent ENT examination by the attending otolaryngologist to rule out any current infection, previous surgery, tympanic membrane perforation, or wax in the external auditory canal. PTA was performed free of cost in the Department of ENT; hence, this study did not put any additional monetary burden on the patients and their families. Air conduction was assessed with headphones for the right and left ear separately for frequencies of 250, 500, 1,000, 2,000, 4,000, and 8,000 Hz. Bone conduction was assessed by using the bone stimulator on the mastoid bone of the skull for the right and left ear separately for frequencies $250,500,1,000,2,000$, and 4,000 $\mathrm{Hz}$. The readings recorded were plotted on the audiogram chart.

Demographic characteristics, such as age, gender, height, and weight, were noted. The most recent serum hemoglobin $(\mathrm{Hb})$ and ferritin levels were noted. Daily doses of DFX $(\mathrm{mg} / \mathrm{kg})$ and duration of use of chelating agent were also recorded.

Data were entered and analyzed on IBM Statistical Package for the Social Sciences (SPSS) Statistics for Windows, Version 21.0. (IBM Corp., Armonk, NY). For quantitative variables, such as age, weight, height, the dose and duration of the chelating agent, $\mathrm{Hb}$, and serum ferritin levels, the mean and standard deviation were calculated. For categorical variables, such as the magnitude of SNHL with frequencies involved compared with the duration and dose of DFX, a Chi-square test was used. The Pearson correlation analysis was used to check the correlation with the chelating agent dose (mg) and duration (months). A pvalue of less than 0.05 was considered as being significant.

\section{Results}

There were 198 cases of major $\beta$-thalassemia included in this study. There were 126 (63.63\%) male and 72 (36.36\%) female participants. Their mean age was $135 \pm 52$ months (range: 60 - 300 months). There were 63 (31.8\%) in the age group 60 - 96 months, 75 (37.9\%) in age group 97 - 144 months, 42 (21.2\%) in age group 145 - 216 months, and 18 (9.1\%) participants were older than 216 months. Their mean weight was $1.3 \pm 0.2$ $\mathrm{kg}$ and the mean height was $25.7 \pm 9.1$ meters.

The mean hemoglobin level of the participants was $7.3 \pm 1.5 \mathrm{gm} / \mathrm{dL}$ and the mean serum ferritin was $5,555.2$ $\pm 5,431.4 \mathrm{mg} / \mathrm{mL}$. The dose and duration of use of chelating agents are presented in Table 1 . Most of the patients $(\mathrm{n}=87 ; 43.9 \%$ ) were taking 700 to $1,000 \mathrm{mg}$ of the chelating agent per day. A chelation duration of 25 - 60 months was most frequent in the study sample. 


\section{Cureus}

Variables

Frequency (\%)

Dose of chelating agent (mg/day)

$<700$

$66(33.3 \%)$

$700-1,000$

$87(43.9 \%)$

$1,000-1,800$

$45(22.7 \%)$

Mean \pm SD

$858.3 \pm 379.1$

Duration chelating agent (months)

$3-6$

$7-12$

$33(16.7 \%)$

$13-24$

$25-60$

$>60$

Mean \pm SD
$30(15.2 \%)$

$45(22.7 \%)$

$51(25.7 \%)$

$39(19.6 \%)$

$34.5 \pm 28.9$

TABLE 1: Descriptive Statistics for Dose and Duration of Chelating Agent of Study Participants (n = 198)

SD: standard deviation

The distribution of SNHL in frequencies of $250,500,1,000,2,000$ and 4,000 Hz in both right and left ears are presented in Table 2. SNHL was found in 39 (19.69\%), 30 (15.15\%), and $30(15.15 \%)$ patients at frequencies $500 \mathrm{~Hz}, 1,000 \mathrm{~Hz}$, and 2,000 Hz, respectively, in the right ear. SNHL was found in 48 (24.2\%), 18 (9.1\%), and 18 (9.1\%) patients at frequencies $2,000 \mathrm{~Hz}, 500 \mathrm{~Hz}$, and 4,000 Hz, respectively, in the left ear. 


\section{Cureus}

Variable

Frequency: $250 \mathrm{~Hz}$

Normal Hearing: 0 - $25 \mathrm{~dB}$

Mild Hearing Loss

Frequency: $500 \mathrm{~Hz}$

Normal Hearing: 0 - $25 \mathrm{~dB}$

Mild Hearing Loss

Frequency: $1,000 \mathrm{~Hz}$

Normal Hearing: $0-25 \mathrm{~dB}$

Mild Hearing Loss

Frequency: $2,000 \mathrm{~Hz}$

Normal Hearing: 0 - $25 \mathrm{~dB}$

Mild Hearing Loss

Frequency: $4,000 \mathrm{~Hz}$

Normal Hearing: 0 - $25 \mathrm{~dB}$

Mild Hearing Loss
SNHL of Right Ear $\mathbf{n}(\%)$

SNHL of Left Ear $\mathbf{n}(\%)$

$189(95.5 \%)$

189 (95. 5\%)

$9(4.5 \%)$

$9(4.5 \%)$

159 (80.3\%)

$180(90.9 \%)$

$39(19.7 \%)$

$18(9.1 \%)$

$168(84.8 \%)$

$183(92.4 \%)$

30 (15.2\%)

$15(7.6 \%)$

$168(84.8 \%)$

$150(75.8 \%)$

30 (15.2\%)

48 (24.2\%)

$183(92.4 \%)$

$180(90.9 \%)$

15 (7.6\%)

$18(9.1 \%)$

TABLE 2: Frequency Distribution of Sensorineural Hearing Loss (SNHL) in Thalassemia Patients ( $n=198)$

dB: decibels; Hz: hertz

In the right ear, 90 (45.5\%) patients were detected with SNHL. In the left ear, 63 (31.8\%) had SNHL. In both ears, the frequency distribution detected was 36 (18.2\%) SNHL in the right or left ear and 54 (27.3\%) had SNHL in both ears (Figure 1).

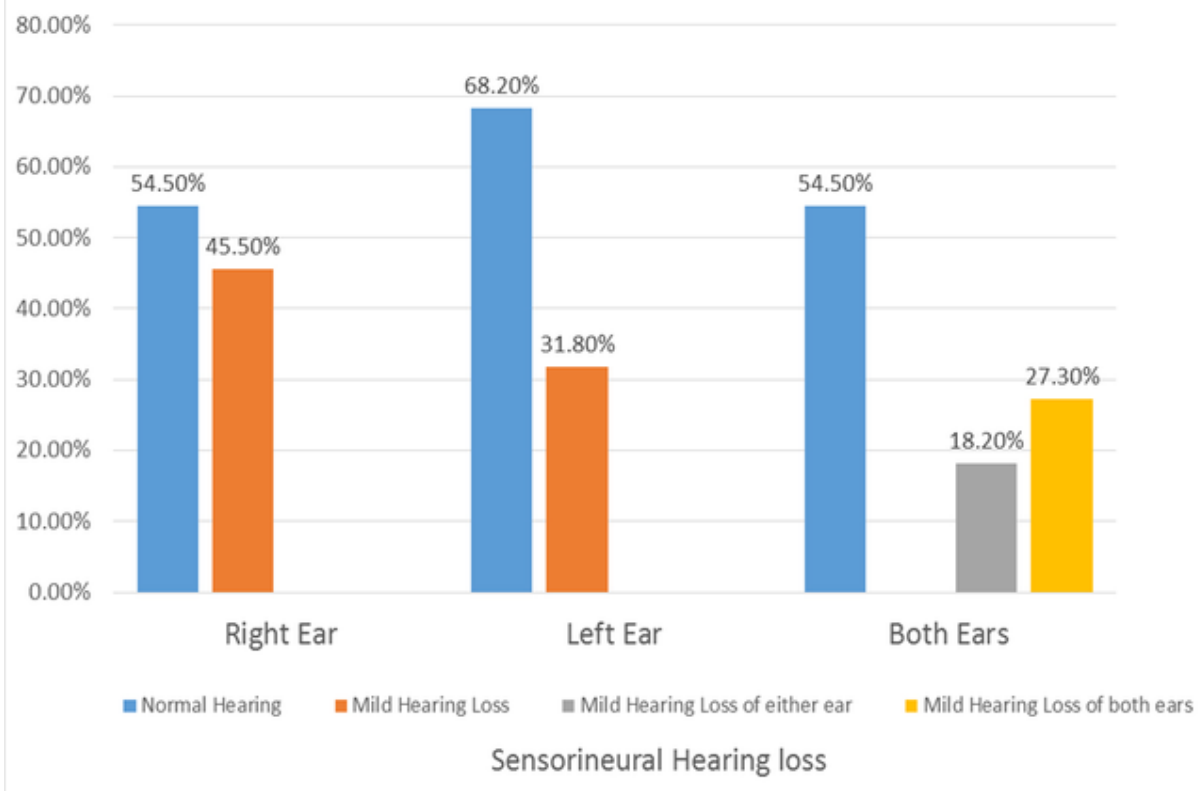

FIGURE 1: Frequency of sensorineural hearing loss detected in either or both ears in thalassemia patients $(n=198)$ 
Correlation of the chelating agent dose and duration with the frequency of SNHL of the right ear is presented in Table 3. The Pearson correlation of the chelating agent dose (mg) with SNHL was statistically significant at frequencies of $250,500,1,000$, and $2,000 \mathrm{~Hz}(\mathrm{p}<0.001,<0.001,0.005$, and 0.003 , respectively) and that of the duration of chelating agent used (in months) with SNHL was statistically significant ( $\mathrm{p}=$ 0.232 and 0.301 at frequencies of 250 and $500 \mathrm{~Hz}$, respectively).

\begin{tabular}{|c|c|c|c|c|c|c|c|c|}
\hline \multirow{2}{*}{ Variable } & \multirow{2}{*}{$\begin{array}{l}\text { Pearson } \\
\text { correlation }\end{array}$} & \multirow{2}{*}{$\begin{array}{l}\text { Chelating agent } \\
\text { dose (mg) }\end{array}$} & \multirow{2}{*}{$\begin{array}{l}\text { Duration of chelating } \\
\text { agent used (months) }\end{array}$} & \multicolumn{5}{|c|}{ Frequency distribution in the right ear } \\
\hline & & & & $\begin{array}{l}250 \\
\mathrm{~Hz}\end{array}$ & $\begin{array}{l}500 \\
\mathrm{~Hz}\end{array}$ & $\begin{array}{l}1,000 \\
\mathrm{~Hz}\end{array}$ & $\begin{array}{l}2,000 \\
\mathrm{~Hz}\end{array}$ & $\begin{array}{l}4,000 \\
\mathrm{~Hz}\end{array}$ \\
\hline \multirow{2}{*}{$\begin{array}{l}\text { Chelating agent dose } \\
\text { (mg) }\end{array}$} & $\mathrm{r}$ & 1 & .216 & .261 & .337 & .198 & .207 & .055 \\
\hline & $\mathrm{p}$ & & .002 & $<0.001$ & $<0.001$ & .005 & .003 & .445 \\
\hline \multirow{2}{*}{$\begin{array}{l}\text { Duration of chelating } \\
\text { agent used (months) }\end{array}$} & $\mathrm{r}$ & .216 & 1 & .232 & .301 & .004 & .032 & .097 \\
\hline & $\mathrm{p}$ & .002 & & .001 & .000 & .960 & 657 & .173 \\
\hline \multirow{2}{*}{ Frequency $-250 \mathrm{~Hz}$} & $\mathrm{r}$ & .261 & .232 & 1 & .893 & .635 & .556 & .291 \\
\hline & $\mathrm{p}$ & $<0.001$ & .001 & & $<0.001$ & $<0.001$ & $<0.001$ & $<0.001$ \\
\hline \multirow{2}{*}{ Frequency $-500 \mathrm{~Hz}$} & $\mathrm{r}$ & .331 & .301 & .893 & 1 & .565 & .536 & .293 \\
\hline & $\mathrm{p}$ & $<0.001$ & $<0.001$ & $<0.001$ & & $<0.001$ & $<0.001$ & $<0.001$ \\
\hline \multirow{2}{*}{ Frequency - 1,000 Hz } & $r$ & .198 & .004 & .635 & .565 & 1 & .611 & .264 \\
\hline & $\mathrm{p}$ & .005 & .960 & $<0.001$ & $<0.001$ & & $<0.001$ & $<0.001$ \\
\hline \multirow{2}{*}{ Frequency - 2,000 Hz } & $\mathrm{r}$ & .207 & .032 & .556 & .536 & 611 & 1 & .253 \\
\hline & $\mathrm{p}$ & .003 & .657 & $<0.001$ & $<0.001$ & $<0.001$ & & $<0.001$ \\
\hline \multirow{2}{*}{ Frequency - 4,000 Hz } & $r$ & .055 & .097 & (291 & .293 & .264 & .253 & 1 \\
\hline & $\mathrm{p}$ & .445 & .173 & $<0.001$ & $<0.001$ & $<0.001$ & $<0.001$ & \\
\hline
\end{tabular}

TABLE 3: Correlation of the Dose and Duration of the Chelating Agent with the Frequency of Sensorineural Hearing Loss in the Right Ear $(n=198)$

$\mathrm{Hz}$; hertz; mg: milligrams; p: p-value; r: correlation coefficient; SD: standard deviation

Correlation of the dose and duration of the chelating agent with a frequency of SNHL of the left ear is presented in Table 4. The Pearson correlation of the chelating agent dose (mg) with SNHL was mildly positive and statistically significant at $0.191,0.202,0.279,0.183$, and 0.221 at frequencies of $250,500,1,000$, 2,000, and 4,000 Hz, respectively. The Pearson correlation of the chelating agent used (in months) with SNHL was weakly positive and statistically insignificant $-0.056,0.039,0.140$, and 0.056 at frequencies of 250 $\mathrm{Hz}, 500 \mathrm{~Hz}, 1,000 \mathrm{~Hz}$, and 4,000 Hz, respectively; however, at the frequency of 2,000 Hz, it was significant at $0.0140(\mathrm{p}=0.049)($ Table 4$)$. 


\section{Cureus}

\begin{tabular}{|c|c|c|c|c|c|c|c|c|}
\hline \multirow[b]{2}{*}{ Variable } & \multirow{2}{*}{$\begin{array}{l}\text { Pearson } \\
\text { correlation }\end{array}$} & \multirow{2}{*}{$\begin{array}{l}\text { Chelating agent } \\
\text { dose }(\mathrm{mg})\end{array}$} & \multirow{2}{*}{$\begin{array}{l}\text { Duration of chelating } \\
\text { agent used (months) }\end{array}$} & \multicolumn{5}{|c|}{ Frequency distribution in the left ear } \\
\hline & & & & $\begin{array}{l}250 \\
\mathrm{~Hz}\end{array}$ & $\begin{array}{l}500 \\
\mathrm{~Hz}\end{array}$ & $\begin{array}{l}1000 \\
\mathrm{~Hz}\end{array}$ & $\begin{array}{l}2000 \\
\mathrm{~Hz}\end{array}$ & $\begin{array}{l}4000 \\
\mathrm{~Hz}\end{array}$ \\
\hline \multirow{2}{*}{$\begin{array}{l}\text { Chelating agent dose } \\
\text { (mg) }\end{array}$} & $r$ & 1 & .216 & .191 & .202 & .279 & .183 & .221 \\
\hline & $\mathrm{p}$ & & .002 & .007 & .004 & .000 & .010 & .002 \\
\hline \multirow{2}{*}{$\begin{array}{l}\text { Duration of chelating } \\
\text { agent used (months) }\end{array}$} & $r$ & .216 & 1 & .056 & .039 & .016 & .140 & .056 \\
\hline & $\mathrm{p}$ & .002 & & .437 & .589 & .824 & .049 & .431 \\
\hline \multirow{2}{*}{ Frequency - $250 \mathrm{~Hz}$} & $r$ & .191 & .056 & 1 & .918 & .729 & .580 & .440 \\
\hline & $\mathrm{p}$ & .007 & .437 & & $<0.001$ & $<0.001$ & $<0.001$ & $<0.001$ \\
\hline \multirow{2}{*}{ Frequency - $500 \mathrm{~Hz}$} & $r$ & .202 & .039 & .918 & 1 & .769 & .516 & .384 \\
\hline & $\mathrm{p}$ & .004 & .589 & .000 & & .000 & $<0.001$ & $<0.001$ \\
\hline \multirow{2}{*}{ Frequency - 1,000 Hz } & $r$ & .279 & .016 & .729 & .769 & 1 & .654 & .406 \\
\hline & $\mathrm{p}$ & $<0.001$ & .824 & $<0.001$ & $<0.001$ & & $<0.001$ & $<0.001$ \\
\hline \multirow{2}{*}{ Frequency - 2,000 Hz } & $r$ & .183 & .140 & .580 & .516 & .654 & 1 & .571 \\
\hline & $\mathrm{p}$ & .010 & .049 & $<0.001$ & $<0.001$ & $<0.001$ & & $<0.001$ \\
\hline \multirow{2}{*}{ Frequency - 4,000 Hz } & $r$ & .221 & .056 & .440 & .384 & .406 & .571 & 1 \\
\hline & $\mathrm{p}$ & .002 & .431 & $<0.001$ & $<0.001$ & $<0.001$ & $<0.001$ & \\
\hline
\end{tabular}

TABLE 4: Correlation of the Dose and Duration of the Chelating Agent and Frequency of the Sensorineural Hearing Loss of the Left Ear $(n=198)$

Hz: hertz; mg: milligrams; p: p-value; r: correlation coefficient; SD: standard deviation

Association of the chelating agent dose and duration with SNHL in either the right or left ear and/or both ears is depicted in Table 5. A higher dose and longer duration of chelation were significantly associated with SNHL. The combined association of the dose and duration of the chelating agent with SNHL of the right or left and both ears were statistically significant. In a dosage of $700-1,000 \mathrm{mg}$ of the chelating agent, 18 (50\%) patients had right or left ear hearing loss, and in the patients using the 1,000-1,800 mg dose of the chelating agent, 27 (50\%) had hearing loss in both ears. In the duration of $>60$ months use of the chelating agent, nine (25\%) patients had right or left ear hearing loss and 18 (33.3\%) had mild hearing loss in both ears, as depicted in Table 5 . 


\section{Cureus}

\begin{tabular}{|c|c|c|c|c|c|c|c|c|c|c|}
\hline \multirow{2}{*}{$\begin{array}{l}\text { Characteristics of } \\
\text { Chelation }\end{array}$} & \multicolumn{3}{|l|}{ Right Ear } & \multicolumn{3}{|l|}{ Left Ear } & \multicolumn{4}{|l|}{ Both Ears } \\
\hline & $\begin{array}{l}\text { No HL n } \\
\text { (\%) }\end{array}$ & HL n (\%) & $\begin{array}{l}\mathrm{P} \text { - } \\
\text { value }\end{array}$ & $\begin{array}{l}\text { No HL n } \\
\text { (\%) }\end{array}$ & HL n (\%) & $\begin{array}{l}\mathrm{P} \text { - } \\
\text { value }\end{array}$ & $\begin{array}{l}\text { No HL n } \\
\text { (\%) }\end{array}$ & $\begin{array}{l}\text { HL in Either Ear } n \\
(\%)\end{array}$ & $\begin{array}{l}\text { HL in Both Ears } n \\
(\%)\end{array}$ & $\begin{array}{l}\text { P- } \\
\text { value }\end{array}$ \\
\hline \multicolumn{11}{|l|}{ Dose (mg/day) } \\
\hline$<700$ & $\begin{array}{l}39 \\
(59.09 \%)\end{array}$ & $\begin{array}{l}27 \\
(40.90 \%)\end{array}$ & \multirow{3}{*}{$<0.001$} & $\begin{array}{l}45 \\
(68.18 \%)\end{array}$ & $\begin{array}{l}21 \\
(31.81 \%)\end{array}$ & \multirow{3}{*}{$<0.001$} & $\begin{array}{l}39 \\
(36.11 \%)\end{array}$ & $9(25 \%)$ & 18 (33.33\%) & \multirow{3}{*}{$<0.001$} \\
\hline $700-1,000$ & $\begin{array}{l}60 \\
(68.96 \%)\end{array}$ & $\begin{array}{l}27 \\
(31.03 \%)\end{array}$ & & $\begin{array}{l}72 \\
(82.75 \%)\end{array}$ & $\begin{array}{l}15 \\
(17.24 \%)\end{array}$ & & $\begin{array}{l}60 \\
(55.55 \%)\end{array}$ & 18 (50\%) & $9(16.66 \%)$ & \\
\hline $1,000-1,800$ & $9(20 \%)$ & $36(80 \%)$ & & $18(40 \%)$ & 27 (60\%) & & $9(8.33 \%)$ & $9(25 \%)$ & 27 (50\%) & \\
\hline \multicolumn{11}{|l|}{ Duration (months) } \\
\hline $3-6$ & $\begin{array}{l}15 \\
(45.45 \%)\end{array}$ & $\begin{array}{l}18 \\
(54.54 \%)\end{array}$ & \multirow{5}{*}{0.004} & $\begin{array}{l}21 \\
(63.63 \%)\end{array}$ & $\begin{array}{l}12 \\
(36.36 \%)\end{array}$ & \multirow{5}{*}{0.007} & $\begin{array}{l}15 \\
(13.88 \%)\end{array}$ & $9(25 \%)$ & $9(16.66 \%)$ & \multirow{5}{*}{0.004} \\
\hline $7-12$ & $18(60 \%)$ & $12(40 \%)$ & & $24(80 \%)$ & $6(20 \%)$ & & $\begin{array}{l}18 \\
(16.66 \%)\end{array}$ & $6(16.66 \%)$ & $6(11.11 \%)$ & \\
\hline $13-24$ & $\begin{array}{l}30 \\
(66.66 \%)\end{array}$ & $\begin{array}{l}15 \\
(33.33 \%)\end{array}$ & & $36(80 \%)$ & $9(20 \%)$ & & $\begin{array}{l}30 \\
(27.77 \%)\end{array}$ & $9(25 \%)$ & $6(11.11 \%)$ & \\
\hline $25-60$ & $\begin{array}{l}33 \\
(64.70 \%)\end{array}$ & $\begin{array}{l}18 \\
(35.29 \%)\end{array}$ & & $\begin{array}{l}36 \\
(70.58 \%)\end{array}$ & $\begin{array}{l}15 \\
(29.41 \%)\end{array}$ & & $\begin{array}{l}33 \\
(30.55 \%)\end{array}$ & $3(8.33 \%)$ & $15(27.77 \%)$ & \\
\hline$>60$ & $\begin{array}{l}12 \\
(30.76 \%)\end{array}$ & $\begin{array}{l}27 \\
(69.23 \%)\end{array}$ & & $\begin{array}{l}18 \\
(46.15 \%)\end{array}$ & $\begin{array}{l}21 \\
(53.84 \%)\end{array}$ & & $\begin{array}{l}12 \\
(11.11 \%)\end{array}$ & $9(25 \%)$ & 18 (33.33\%) & \\
\hline
\end{tabular}

\section{TABLE 5: Association of the Chelating Agent Dose and Duration with SNHL in Either the Right or}

Left Ear and/or Both Ears $(n=198)$

HL: hearing loss; SNHL: sensorineural hearing loss

\section{Discussion}

Of the 198 cases of major $\beta$-thalassemia patients, 108 (54.54\%) had normal hearing and 98 (45.45\%) had sensorineural hearing loss. We found SNHL in $\beta$-thalassemia major patients at all doses of DFX from 700 to $1,800 \mathrm{mg}(\mathrm{p}<0.001)$. It was also revealed that SNHL was found in $\beta$-thalassemia major patients at all durations of use, from three to 60 months or more $(\mathrm{p}<0.007)$.

This study showed a prominent relationship between the chelating agents and SNHL. Where literature has been reported on the relationship between SNHL and the dosage of chelating agents, not much data exists on the relationship between SNHL and the duration of use of chelating agents in $\beta$-thalassemia [18-19, 24]. This study has provided substantial proof regarding hearing loss in $\beta$-thalassemia major patients after a longer duration of DFX usage. To the best of our knowledge, this is the first-ever study conducted in Pakistan regarding SNHL in $\beta$-thalassemia major patients after the use of DFX and the correlation with its dose and duration of use. However, this study was limited by a low budget, time constraint, lack of cooperation from patients due to the language barrier, and the fact that cases were included from one city only.

A study conducted by Yadav et al. in Haryana, India in 2012 showed that increasing duration of use of the chelating agent caused an increased incidence of SNHL in $\beta$-thalassemia major patients [25]. A crosssectional study carried out by Kong et al. in Malaysia in 2014 showed a $57.4 \%$ frequency of SNHL in $\beta$ thalassemia major patients. A total of 54 patients were included with the age ranging from three years and above [24]. Another descriptive-analytical study was done by Ashrafi et al. in 2011 on $80 \beta$-thalassemia major patients aged four to 32 years, in which $47 \%$ had SNHL with a significant relationship $(\mathrm{p}<0.05)$ of hearing loss with dose and duration of DFX [26].

Kong et al. revealed a significant positive correlation between the dose and frequency of 2,000 $\mathrm{Hz}$ and 4,000 $\mathrm{Hz}$ on a pure tone audiometry test in the left ear. No significant correlation was observed in the right ear [24]. In another study performed by Osma et al. in 2015 from Turkey, right ear SNHL was 39\%, while the left ear SNHL was $27.7 \%$ [27]. The findings of these studies are in conjunction with our study. 
A study by Vir et al. disclosed that patients taking an injectable iron-chelating agent for three years had a low incidence of SNHL as compared to those taking therapy for six years [28]. Other studies also showed a strong relationship between SNHL with the dose and duration of the chelating agent in $\beta$-thalassemia major patients [27, 29].

A negative correlation result between ototoxicity and DFX treatment was reported in a study from Thailand [30]. They analyzed their clinical records from January 1997 to December 2010. All transfusion-dependent thalassemia patients received iron chelation therapy with mono DFX, DFO, or a combination. One hundred thalassemia patients were enrolled and analyzed. SNHL was detected in seven patients but only four were determined to be associated with iron chelators. They reported that there was a rather low incidence of ototoxicity after exposure to iron chelators [30]. In another paper by Derin et al., DFP and DFX were found to be unrelated to SNHL in $\beta$-thalassemia major patients [22]. The findings of these studies did not correlate with our study. In our study, $45.45 \%$ of patients had SNHL in the right ear compared to the left ear (31.81\%). There was a significantly positive correlation between the dose of the chelator and frequencies of $250 \mathrm{~Hz}, 500 \mathrm{~Hz}, 1,000 \mathrm{~Hz}$, and $2,000 \mathrm{~Hz}$ in the right ear, while a positive correlation between the dose and frequency was observed from $250 \mathrm{~Hz}$ to $4,000 \mathrm{~Hz}$ in the left ear. Considering the duration, there was a positive correlation at $250 \mathrm{~Hz}$ to $500 \mathrm{~Hz}$ in the right ear. In the left ear, we found positive correlations at the frequency of $2,000 \mathrm{~Hz}$.

PTA was used to determine the hearing status of patients in this study. In a study conducted by Jiang et al. in 2016, PTA included routine PTA and extended high-frequency audiometry in 60 patients from September 2013 to October 2014 [30]. The results showed that extended high-frequency might be more sensitive in the determination of early SNHL for $\beta$-thalassemia major patients. This does not concur with our findings. It is recommended that PTA should be done regularly for every $\beta$-thalassemia patient taking a chelating agent. A large study should be done to further evaluate the results. More sophisticated, advanced methods of detection and monitoring the hearing acuity, such as brain-evoked response audiometry and otoacoustic emission, may be performed for a patient who has sensorineural hearing loss.

\section{Conclusions}

Although a definitive cure of thalassemia is a bone marrow transplant, regular blood transfusions (along with chelation therapy) prolong the life of patients. Chelation therapy, while having these benefits, also leads to some complications. With this survey, it was concluded that almost half of the patients had normal hearing, while the other half had sensorineural hearing loss after the use of DFX. It is inferred that the incidence of SNHL is not only dose-related but the duration of use of a chelating agent is also a contributing factor since SNHL was found to be significantly associated with both the dosage and duration of use of a chelating agent.

\section{Additional Information \\ Disclosures}

Human subjects: Consent was obtained by all participants in this study. Dow University of Health Sciences Ethics Committee issued approval 393/DUHS/Approval/2015. Animal subjects: All authors have confirmed that this study did not involve animal subjects or tissue. Conflicts of interest: In compliance with the ICMJE uniform disclosure form, all authors declare the following: Payment/services info: All authors have declared that no financial support was received from any organization for the submitted work. Financial relationships: All authors have declared that they have no financial relationships at present or within the previous three years with any organizations that might have an interest in the submitted work. Other relationships: All authors have declared that there are no other relationships or activities that could appear to have influenced the submitted work.

\section{References}

1. Cooley TB: A series of cases of splenomegaly in children with anemia and peculiar bone changes . Trans Am Pediat Soc. 1925, 37:29-30.

2. McGann PT, Nero AC, Ware RE: Clinical features of beta-thalassemia and sickle cell disease . Adv Exp Med Biol. 2017, 1013:1-26. 10.1007/978-1-4939-7299-9_1

3. Eleftheriou A: About thalassemia. Thalass Int Pub. 2003, 2:11-12.

4. Fawdry A: Erythroblastic anaemia of childhood (Cooley's anaemia) in Cyprus. Lancet. 1944, 243:171-76. 10.1016/S0140-6736(00)42998-3

5. Weatherall D: The Thalassemias. Williams Hematology, 6th ed. Beutler E, Lichtman MA, Coller BS, Kipps TJ, Seligsohn U (ed): McGraw-Hill, New York; 2001. 487:562-64.

6. Colah R, Gorakshakar A, Nadkarni A: Global burden, distribution and prevention of $\beta$-thalassemias and hemoglobin E disorders. Expert Rev Hematol. 2010, 3:103-17. 10.1586/ehm.09.74

7. Ansari SH, Shamsi TS: Thalassaemia prevention programme. Haematol Update. 2010, 23-28.

8. Asif N, Hassan K: Prevention of beta thalassemia in Pakistan. J Islam Med Dent Coll. 2014, 5:152-53.

9. Rahim F: Microcytic hypochromic anemia patients with thalassemia: genotyping approach. Indian J Med Sci. 2009, 63:101-108.

10. Origa R: Beta-thalassemia. GeneReviews ${ }^{\circledR}$. Adam MP, Ardinger HH, Pagon RA, et al (ed): University of Washington, Seattle (WA); 2000. 
11. Origa R, Moi P: Alpha-thalassemia. GeneReviews ${ }^{\circledR}$. Adam MP, Ardinger HH, Pagon RA, et al (ed): University of Washington, Seattle (WA); 2005.

12. Higgs DR, Gibbons RJ: The molecular basis of alpha-thalassemia: a model for understanding human molecular genetics. Hematol Oncol Clin North Am. 2010, 24:1033-54. 10.1016/j.hoc.2010.08.005

13. Aarabi B, Haghshenas M, Rakeii V: Visual failure caused by suprasellar extramedullary hematopoiesis in beta thalassemia: case report. Neurosurgery. 1998, 42:922-25. 10.1097/00006123-199804000-00134

14. Sinniah D, Vignaendra V, Ahmad K: Neurological complications of beta-thalassaemia major. Arch Dis Child. 1977, 52:977-79. 10.1136/adc.52.12.977

15. Ehlers KH, Giardina PJ, Lesser ML, Engle MA, Hilgartner MW: Prolonged survival in patients with betathalassemia major treated with deferoxamine. J Pediatr. 1991, 118:540-45. 10.1016/s0022-3476(05)83374-8

16. Mishra AK, Tiwari A: Iron overload in beta thalassaemia major and intermedia patients . Maedica (Buchar). 2013, 8:328-32.

17. Molavi M, Doozandeh H, Nazemi A, Evazi R, Mansoori F: Comparison of therapeutic response and complications of oral osveral and injection desfereal chelating agent in patient with thalassemia major. Asian J Med Pharm Res. 2013, 3:93-97.

18. Kontzoglou G, Koussi A, Tsatra J, Noussios G, Vital V, Sagarakis G, Athanassiou M: Sensorineural hearing loss in children with thalassemia major in Northern Greece. Int J Pediatr Otorhinolaryngol. 1996, 35:223-30. 10.1016/0165-5876(95)01308-3

19. Cohen A, Martin M, Mizanin J, Konkle DF, Schwartz E: Vision and hearing during deferoxamine therapy. J Pediatr. 1990, 117:326-30. 10.1016/S0022-3476(05)80556-6

20. Ejaz MS, Baloch S, Arif F: Efficacy and adverse effects of oral chelating therapy (deferasirox) in multitransfused Pakistani children with $\beta$-thalassemia major. Pak J Med Sci. 2015, 31:621-25. 10.12669/pjms.313.6972

21. Al-Khabori M, Bhandari S, Al-Huneini M, Al-Farsi K, Panjwani V, Daar S: Side effects of deferasirox iron chelation in patients with beta thalassemia major or intermedia. Oman Med J. 2013, 28:121-24. 10.5001/omj.2013.31

22. Derin S, Azik FM, Topal Y, et al.: The incidence of ototoxicity in patients using iron chelators . J Int Adv Otol. 2017, 13:136-39. 10.5152/iao.2016.1852

23. Faramarzi A, Karimi M, Heydari ST, Shishegar M, Kaviani M: Frequency of sensory neural hearing loss in major beta-thalassemias in Southern Iran. Iran J Pediatr. 2010, 20:308-12.

24. Yadav M, Yadav J, Tiwari AD, Abrol P, Sood S: Effect of iron chelating agents desferrioxamine, deferiprone and their combination on brainstem auditory evoked potential (BAEP). JK-Practitioner. 2011, 17:29-34.

25. Kong MH, Goh BS, Hamidah A, Zarina AL: The prevalence of sensorineural hearing loss in betathalassaemia patient treated with desferrioxamine. Med J Malaysia. 2014, 69:9-12.

26. Ashrafi M, Mohammadzadeh A: Hearing status of thalassemic patients treated with dessfroxamin . J Kermanshah Univ Med Sci. 2011, 15:e79024.

27. Osma U, Kurtoglu E, Eyigor H, Yilmaz MD, Aygener N: Sensorineural hearing loss in beta-thalassemia patients treated with iron chelation. Ear Nose Throat J. 2015, 94:481-85. 10.1177/014556131509401206

28. Vir D, Panda NK, Marwaha RK: Desferioximine induced ototoxicity in thalassemic patients. Ann Neurosci. 2010, 17:182-84. 10.5214/ans.0972.7531.1017407

29. Shamsian BS, Aminasnafi A, Moghadassian H, et al.: Sensory neural hearing loss in beta-thalassemia major patients treated with deferoxamine. Pediatr Hematol Oncol. 2008, 25:502-508. 10.1080/08880010802234911

30. Tanphaichitr A, Kusuwan T, Limviriyakul S, et al.: Incidence of ototoxicity in pediatric patients with transfusion-dependent thalassemia who are less well-chelated by mono-and combined therapy of iron chelating agents. Hemoglobin. 2014, 38:345-50. 10.3109/03630269.2014.940462 